\title{
Meta-Metaphysics
}

\author{
BERNARD RICCA \\ St. John Fisher College (USA)
}

It is perhaps appropriate that a physicist puts forth an advance organizer to the three papers that follow in this special issue, for all three papers - and indeed all the papers of this issue - deal with issues that are commonly labeled as "metaphyiscs". By my writing this, these papers are perhaps doubly metaphysical; being "after" physics both by topic and by location, and hence, meta-metaphysical. (Paradoxically, the papers that occur in this issue after the physicist's paper were all written temporally before the physicist's introduction!)

In a more serious vein, all of these papers have a distinct sense of after-ness that moves them beyond the usual metaphysics. Aristotle's Metaphysics was, at least partly, an attempt to reconcile a number of dichotomies: Plato's eternal forms and the observation of a changing reality, the ever-changing reality of Heraclitus and the stasis of Parmenides, among others. This program of reconciling dichotomies has continued to the present day. Despite the long history of relatively limited, although often extremely beneficial, successes that have been brought about by this program, it is only with the emergence of complexity thinking that a substantially new program is coming about, one that in many regards is truly meta-metaphysics. ${ }^{1}$

This new program shares characteristics with any program: the participants adopt particular stances towards ontology, epistemology and the like, make various assumptions about the nature of the world, and so on. All of these are the usual components of metaphysics. However, there are things that are radically different about complexity encountering these ideas. These differences - differences that make a difference, to borrow from Bateson - include an explicit recognition of and privileging of the system, a focus on relationship and a more refined attempt to explore the encounter with boundaries.

Complexity brings forth a new notion of system. From the classical physics notion of system through the early systems theorists, a system was well-defined, welldelineated, and above all, separated from other systems and the researchers who study them. While approaches other than complexity consider researchers to be connected in some way to the system under study, complexity most clearly recognizes the inappropriate-ness of the reductionist approach and shows how closely enmeshed

\footnotetext{
${ }^{1}$ There are others who talk of "metametaphysics" (e.g., Chalmers, 2009) but they do so as a way of defending metaphysics rather than as a way of moving beyond metaphysics. I will use the hyphenated version to distinguish our conversation from those discussions.
} 
systems (including the researcher!) are with each other (Kampis, 1994; Ricca, 2008; Taylor, 2005). As Reynolds (2005) notes, words do not have meaning, and words do not have meaning in relationship to each other. Words have meaning only in the relationship the words have to our own experiences. Relatively few systems can be examined except in relationship to other systems and the people doing the examining.

Relationships, therefore, also take on a new position in meta-metaphysics. Most discourse still implies that things-have-relationships or things-are-related, and our language still reflects those implications. However, Bateson (1979) and Morin (2008), among others, push us to examining relationship as the essence of systems rather than as a merely something that links one important thing to another. Indeed, it is not possible for a complex system to be considered without its relationships, and so we cannot break relationships. As Bateson (1979) says, "remove the pattern that connects" (p. 9) and all the important things are lost.

If relationships cannot be easily severed, then the boundaries that do separate one system from another must be crossed with great care. (I'll put aside for the time being the problematic nature of boundaries.) It is common, for example, to think metaphorically, bringing (part of) one system over to another and grafting it there. While such metaphorical use of one system can be "good to think with" (Levi-Strauss, 1963) there are dangers to this thinking. First, a metaphorical approach too often brings only part of the thinking over, severing the relationships that constitute the original system and thereby destroying the source of the metaphor. In a related way, applying one type of thought to another system also may fail to recognize the relationships of the target system, thereby breaking that system. Further, there is even an often implicit notion that the source system is privileged over the target system; this attempts to create a relationship which may be at odds with the natures of those systems.

It is these three senses of after-ness that are exhibited in the papers in this section.

\section{Three papers}

In a real sense, these three differences situate complexity not as postmodern, or perhaps not just as post-modern, but rather as meta-metaphysics. Each of the three papers of this section explores this after-ness in different ways.

Doll reexamines curare from the perspective of a complexivist. After presenting a history of curriculum, Doll moves into an examination of complexity/chaos and its implications for curriculum. In doing this, Doll draws from Kauffman (1993, 1995, 2002) whose foci are on organization, holism, and new approaches. ${ }^{2}$

Each of Kauffman's foci fit into a complexity view and are much more than just attempts to reconcile dichotomies. For example, Kauffman does not attempt to reconcile the notions of random events with those of centralized control (or even intelligent design) in examining evolution. Instead, Kauffman chooses a different path that uses feedback loops to step out of the random/controlled continuum. In basing his approach on Kauffman, Doll firmly sets up to promote systems, heart and relations. As Doll says, "[t]he best of a [complex] system view is one of relations" (Doll, this issue). In taking this approach, Doll neatly steps out of the process vs. product debate of school curricula. There is no need to "reconcile" time spent in a classroom on process or product, for they are each components of a complex system: neither exists without the other, both bootstrap each other via feedback loops, and neither process nor product is the system of curriculum. In this way, the complexity approach to the question "Which came first...?"

\footnotetext{
${ }^{2}$ Since the original publication of Doll's writing, Kauffman's more recent work, Reinventing the Sacred (2010), explicitly puts spirituality in with complexity. In this process, there is another sense of after-ness that must be addressed. Although Doll does intimate that spirituality is part of the complexity program, he does not pursue that line here.
} 
or "Which is more important...?" is often to respond that "a circle has no beginning" (Rowling, 2007, p. 587).

While Doll's focus is explicitly on curriculum, Gough examines "methodological borrowing," the common (mis-)application of one field's ideas to another. Gough's examination is largely a cautionary one, however. He considers both the sources and targets of applications as complex systems - whole, related, and possessing boundaries and looks for ways to apply one methodology to another field without breaking either field. Sadly, the examples Gough brings forth all have serious shortcomings, and the reader would not have to look hard to find other flawed borrowings.

Looking a bit deeper at what Gough brings forth we find that borrowed methodologies must always match their target in typology. In particular, systems can be simple (linear) or complex (and probably others), relationships can demonstrate many different topologies, etc. There are many different lenses through which to look at a system and all of these lenses need to provide the same view of a source and a target. One interesting point that is raised for me in all of this, however is the question of whether or not these issues are important in principle or in practice. This question has been debated for some time in the chaos literature without a clear outcome. We perhaps borrow methodologies because they are close enough "for all practical purposes"; whether or not that is acceptable in a complex system is unclear (at least to me).

One important part of Gough's work here is that it demonstrates a bootstrapping that I believe to be part of meta-metaphysics: The complexity program is created by its own application, and the applications emerge as the program evolves. This is yet another way in which complexity can move past metaphysics.

Davis \& Sumara also demonstrate an after-ness in their piece. Indeed, they explicitly refer to "Complexity 1.0", "Complexity 2.0" and "Complexity 3.0" as stages within complexity. And, at least in Complexity 3.0 (which is the focus of their argument) they also step out of the various dichotomies that have plagued us since the time of Aristotle. As they state "[education] is charged with the tasks of supporting the wellness and possibility of individuals while supporting the maintenance and evolution of society" (Davis \& Sumara, this issue). In statements such as this, we see that Complexity 3.0 allows us to escape multiple levels (for lack of a better term) of dichotomies individual/society and maintenance/change - simultaneously.

The five "game changers" highlighted by Complexity 3.0 have led, at least in some places, to innovations. In a very real sense, the connections of "game changers" to the innovations seem almost trivial or obvious. However, it must be noted that the connections are only obvious because Davis \& Sumara move the debate beyond the usual dichotomies, and use methodologies that are not so much "borrowed" as they are invented, demonstrating again the same bootstrapping as seen in Gough.

\section{Onward!}

All three papers both demonstrate ways in which complexity has moved beyond the usual educational and/or philosophical debates and applications while simultaneously pointing towards other open and largely unexplored fields. Readers will certainly enjoy these papers and be intrigued by their possibilities.

\section{References}

Bateson, G. (1979). Mind and nature: A necessary unity. Cresskill, NJ: Hampton Press.

Chalmers, D., Manley, D., \& Wasserman, R. (Eds.), (2009). Metametaphysics: New essays on the foundations of ontology. Oxford, UK: Oxford University Press.

Kauffman, S. (1993). The origins of order. Oxford, UK: Oxford University Press.

Kauffman, S. (1995). At home in the universe. Oxford, UK: Oxford University Press.

Kauffman, S. (2002). Investigations. Oxford, UK: Oxford University Press.

Kauffman, S. (2010). Reinventing the sacred. New York, NY: Basic Books. 
Kampis, G. (1994). Biological evolution as a process viewed internally. In H. Atmanspacher, \& G. Dalenoort, (Eds.). Inside versus outside. New York, NY: Springer-Verlag.

Levi-Strauss, C. (1963). Totemism. R. Needham (trans.). Boston, MA: Beacon.

Morin, E. (2008). On complexity. Cresskill, NJ: Hampton Press.

Reynolds, S. (2005). Learning is a verb. Phoenix, AZ: Holcomb-Hathaway.

Ricca, B. (2008). Enframing: The view from within. Complicity 5 (1), 115-119.

Rowling, J. K. (2007). Harry Potter and the Deathly Hallows. New York, NY: Arthur A. Levine Books.

Taylor, P. (2005). Unruly complexity. Chicago, IL: University of Chicago Press.

(c) Copyright 2012. The author, Bernard Ricca, assigns to the University of Alberta and other educational and non-profit institutions a non-exclusive license to use this document for personal use and in courses of instruction provided that the article is used in full and this copyright statement is reproduced. The authors also grant a non-exclusive license to the University of Alberta to publish this document in full on the World Wide Web, and for the document to be published on mirrors on the World Wide Web. Any other usage is prohibited without the express permission of the authors. 